\title{
Non Genomic Modulation of Ligand Gated Ionotropic Receptors by Thyroid Hormones
}

\author{
Giulia Puia*
}

Department of Biomedical Sciences, University of Modena and Reggio Emilia

\begin{abstract}
Ligand gated ionotropic receptors are responsible for the fast neurotransmission in the brain and are the target of widely used drugs, such as anxiolytics, anticonvulsant and antidepressant, and of endogenously produced substances, e.g. hormones. In this review, the fast regulatory effects of thyroid hormones (THs; T3 and T4) on ligand gated ion channels will be analyzed and discussed. More precisely, the focus will be on receptors that mediate the majority of inhibitory and excitatory neurotransmission in the brain, respectively $\gamma$-aminobutyric acid (GABA) and glutamate ionotropic receptors. Brain is an important target for THs, as proved by the profound alterations in its structure and functionality related to their imbalance. Indeed, dysthyroidism is often associated with several neuropsychiatric disorders that derive also from a dysfunction of GABAergic and glutamatergic neurotransmission. The molecular mechanisms responsible for these changes are not completely clarified yet. THs, through the binding of nuclear receptors, can modulate the expression of proteins directly or indirectly involved in neurotransmission; in addition, their non genomic fast modulation of ionotropic receptors mediating excitatory and inhibitory neurotransmission could also play an important role. THs modulate recombinant and native receptors activated by exogenous GABA or glutamate as well as synaptic and extrasynaptic excitatory and inhibitory neurotransmission. These non genomic effects do not depend on protein phosphorylation or on the membrane integrin receptor $\alpha v \beta 3$ activation. Keeping in mind that a local regulation of THs levels can occur in different brain regions the fast modulation of THs on synaptic activity could provide a rapid and efficacious control of the function of several brain circuitries.
\end{abstract}

Keyworlds: Electrophysiology, endogenous modulators, $\mathrm{GABA}_{\mathrm{A}}$ receptors, Glutamate receptors, ligand-gated receptors, neurosteroids, synaptic transmission, thyroid hormones non genomic effects.

\section{INTRODUCTION}

Ligand gated ionotropic receptors (LGiRs) are heteromeric proteins coupled to a channel whose gating depends on the binding of a neurotransmitter. Usually LGiRs are localized at synapses and convert the chemical signal of the neurotransmitter directly in electrical signal on the postsynaptic membrane ensuring a fast synaptic transmission. To this class of receptors belong nicotinic acetylcholine (nAch), serotonin $5 \mathrm{HT}_{3}, \mathrm{GABA}_{\mathrm{A}}$, glycine, ionotropic glutamate (iGLUT) and P2X receptors. The basic biophysical and pharmacological properties of LGiRs were determined with the help of molecular biology techniques that allowed cloning and expression of recombinant receptors in heterologus systems. Most of LGiRs are associated with accessory proteins and with different types of structures involved in receptor trafficking. The activity of LGiRs is finely regulated by exogenous and endogenous substances that could directly bind the receptors or indirectly modulate their function through post-transcriptional modifications such as phosphorylation [1]. Among the endogenous molecules that can play an important role as modulators of LGiRs are thyroid

*Address correspondence to this author at the Department of Biomedical Sciences, University of Modena and Reggio Emilia, via Campi, 287, 41100 Modena, Italy; Tel: +390592055135; Fax: +390592055376;

E-mail: puja@unimore.it hormones (THs). The importance of THs on neurotransmission mediated by LGiRs, is supported by the evidence that deficit in THs level during development causes profound alterations in structure and function of the brain [2-4]. In addition, dysthyroidism in adult life is associated with several psychiatric disorders such as anxiety, depression, memory deficits, hallucinations and in severe cases seizures $[5$, 6]. For these reasons, animal models of hypo- or hyperthyrodism were always considered a valuable tool to shed light on the effect of THs in the central nervous system (CNS).

Adult onset hypothyroidism has been clearly linked to cognition and memory dysfunction both in animal models [7] and in humans [5]. Hypothyroidism has been shown to affect basic synaptic neurotransmission, short-term and longterm plasticity in hippocampus, a brain area known to be involved in memory processes.

A large amount of studies has been carried on in the last years on this topic but they did not provide a clear view of the changes in brain synaptic transmission when THs levels are altered. Basal neurotransmission was found to be decreased $[8,9,10,11]$, enhanced [12] or unaffected $[13,14]$ by THs imbalance. Long-term potentiation (LTP) [15], a widely accepted cellular model for long-term synaptic plasticity related to learning and memory, was also found to be increased $[8,10,12]$, suppressed $[11,13,14,16]$ or unchanged [16] after THs deficit. 
Mechanisms underlying THs modification of synaptic neurotransmission could be mediated by protein synthesis and be considered "genomic" $[17,18,2]$, or depend on fast changes not dependent on transcriptional mechanisms and be, for this reason, called "non genomic". Many of the non genomic actions of THs are initiated in the plasma membrane, at the level of the $\alpha v \beta_{3}$ integrin receptor $[19,20]$, or in the cytoplasm. These effects, opposite to the genomic ones, are prompt in onset, independent of new protein synthesis, associated with changes in ion transport systems or lead to complex cellular modifications [21]. The non genomic events could also ultimately result in transcriptional modification of specific genes [20,21].

The genomic mechanisms have been extensively investigated but studies on non genomic effects of THs at the level of synaptic neurotransmission were limited.

Dratman in 1976 [22] proposed a role for T3 as neurotransmitter based on the findings that $\mathrm{T} 3$ localize in the nerve ending fractions. Mason [23], supporting this view showed that T3 could be released from synaptosomes with $\mathrm{Ca}^{2+}$ dependent mechanisms. Further studies provided evidences for a selective distribution of labeled THs and of antibody against T3 in specific brain areas of the adrenergic system $[24,25]$. A naturally occurring metabolite of THs, the thyronamine $\mathrm{T}_{1} \mathrm{AM}$ can rapidly activate a G-protein coupled receptor and stimulate adenylate cyclase [26], and in a recent report evidences were provided of its physiological role in the brain as adrenergic blocking agent [27].

In an electrophysiological study, Caria et al. [28] showed that T4 inhibits field excitatory postsynaptic potentials in hippocampus in vivo. In in vitro studies performed on CA1 neurons in slices, the same group showed that $\mathrm{T} 3$ and $\mathrm{T} 4$ have opposite effects on noradrenaline-evoked firing rate: $\mathrm{T} 4$ reduces while $\mathrm{T} 3$ enhances cell firing rate.

Various other neurotransmitter systems, such as cholinergic, serotoninergic, adenosinergic, and dopaminergic are affected by THs $[18,29]$ but while the contribution of genomic mechanisms in THs modulation is acknowledged, their fast non-genomic effects at the level of these systems have not been investigated yet.

In this paper information concerning the non genomic effects of THs on two of the major players in the fast synaptic transmission in the CNS, i.e. iGLUT and $\mathrm{GABA}_{\mathrm{A}}$ receptors will be reviewed.

\section{NON GENOMIC REGULATION OF IONOTROPIC GLUTAMATE RECEPTORS BY THYROID HOR- MONES}

\section{Ionotropic Glutamate Receptors: General Features}

Glutamate receptors mediate the majority of excitatory neurotransmission in CNS and are localized on neuronal and non-neuronal cells. They are classified, according to the signal transduction mechanism, in ionotropic (iGLUT) or metabotropic (mGLUT). Three classes of iGLUT receptors have been identified: $\alpha$-amino-3-hydroxy-5-methyl-4isoxazole-propionic acid (AMPA), kainate, and N-methyl-Daspartic acid (NMDA) receptor [30].
All iGLUT receptors are assembled from different subunits (AMPA receptor: GLUA1-4, kainate receptor: GLUK1-5, NMDA receptor: GLUN1-4) whose expression is developmentally regulated and brain region specific. The different subunit combination confers to the receptors diverse physiological and pharmacological properties [30]. Several drugs are known to act at the level of these receptors by potentiating or by blocking their activities. Among them are substances that antagonize glutamatergic neurotransmission that are potential therapeutic agents in neurodegenerative diseases, when an excess of glutamate could be responsible for neuronal death [30].

On the other side, compounds able to potentiate glutamate receptor function are considered nootropic drugs that improve cognitive performance and are potential medications for a number of psychiatric and neurological conditions [30].

A large amount of exogenous substances modulate glutamatergic neurotransmission but endogenous compounds able to regulate its functionality are relatively limited (monoand divalent ions, polyamines, kinurenine and steroid molecules) [30]. There are steroid molecules that are synthesized in the brain and called neurosteroids (NSs) [31]. The central effects of these compounds are mediated by interactions with several neurotransmitter-gated channels [32], including AMPA and NMDA receptors.

\section{Ionotropic Glutamate Receptors and Thyroid Hormones}

Preliminary evidence of an interaction between THs and glutamate receptors was provided by Oguro et al. [33], who found that THs displace NMDA-sensitive L- $\left({ }^{3} \mathrm{H}\right)$ glutamate binding competitively.

Recently, it has been shown that THs are able to modulate glutamatergic neurotransmission in hippocampal neurons in primary cultures and in slices [34]. T3 and T4 reduced NMDA-evoked currents with potency in the micromolar range and the effect is not competitive for the glutamate or the glycine binding site. T3 and T4 were active in mouse fibroblasts expressing NR1a-NR2A, NR1a-NR2B subunits of the NMDA receptors, and no subunit selectivity was detected. In Figure 1 are shown the effects of T3 on NMDAevoked current either on cultured neurons (Fig.1A) or in mouse fibroblast expressing NR1-NR2a (Fig.1B).

Since NMDA receptors are known targets for protein kinases [30], the hypothesis that THs effect could occur via PKC-mediated phosphorylation of the channel was tested. The effect was not achieved through this mechanism because neither blocking nor stimulating the kinase had an effect on the inhibition. AMPA and Kainate -evoked currents were also inibited by T3 but not by T4 [34].

Analysis of the effect of THs on synaptic transmission in hippocampal slices show that only T3 is active on excitatory postsynaptic currents (EPSCs). This hormone reduces the frequency of the events (see Fig.1C) but leaves unaffected peak and decay of the currents [34]. The authors suggest that T3 reduces the release of neurotransmitter through modulation of presynaptic glutamatergic receptors or other types of receptors, e.g. nicotinic $\alpha 7$ or sigma receptors [35]. 


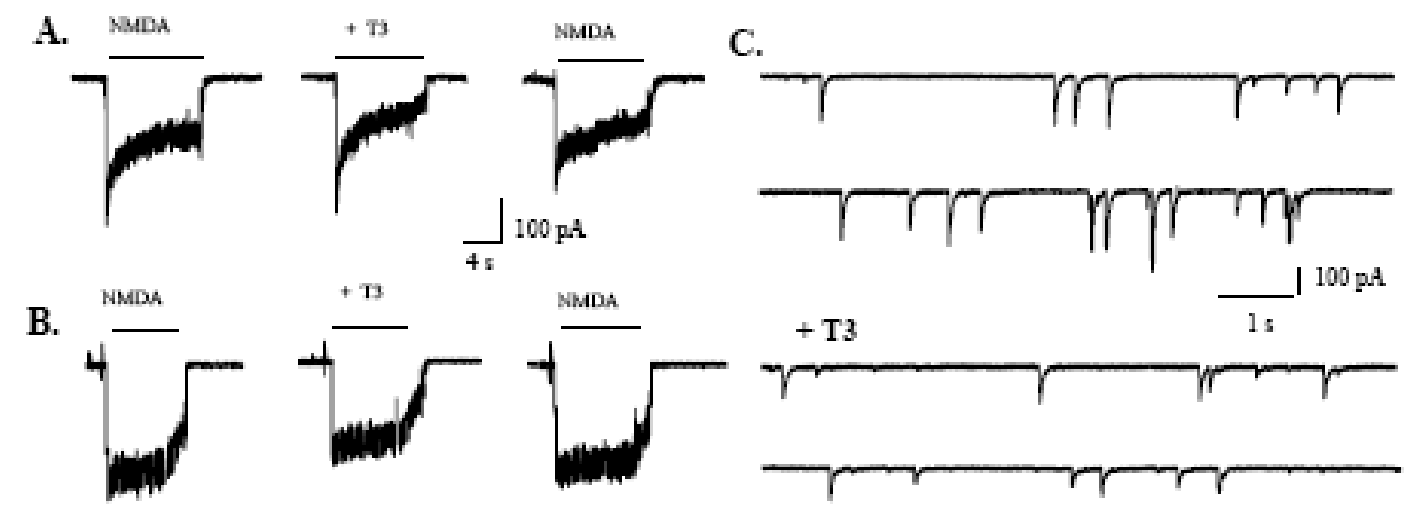

Fig. (1). Modulatory effects of THs on native and recombinant NMDA receptors.

A). Representative traces showing the effect of $\mathrm{T} 3(10 \mu \mathrm{M})$ on NMDA $(100 \mu \mathrm{M}+$ glycine $10 \mu \mathrm{M})$-evoked currents in primary culture of hippocampal neurons. The effect of T3 is reversible. B). NMDA-evoked current recorded in fibroblasts stably expressing NR1-NR2a subunits of the NMDA receptor. The current is reduced by the application of T3 $(10 \mu \mathrm{M})$. C.) Spontaneous excitatory postsynaptic currents (sEPSCs) recorded from a pyramidal neuron of the hippocampus from a 15 days old rat slice, in control (upper traces) and after bath perfusion of T3 $(20 \mu \mathrm{M}$; lower traces). All experiments were performed using the patch-clamp technique in whole cell configuration.

Changes in the release of neurotransmitter could also depend on the dynamic of cytoskeleton remodeling at the presynaptic terminal, indeed there are several evidence of THs effect at the level of cytoskeleton protein $[36,37,38]$.

Glutamate is fundamental for the neurotransmission in the brain and for the processes of learning, but an increase in the aminoacid concentration produces an excessive activation of the receptors that can lead to neuronal death [39]. Considered the antagonistic effect of THs on iGLUTR, it is likely that they could have a neuroprotective role against glutamate-induced toxicity. Indeed Losi et al. [34] observed that THs, at concentrations similar to those active on NMDA and AMPA receptors, prevent glutamate-induced neuronal death in cortical cultures. Similarly Mendes-de-Aguiar et al. [40] showed that also in cerebellar primary cultures THs protect from glutamate-induced neuronal death. The effect was achieved mainly through an increased synthesis of the glutamate transporters GLAST and GLT-1 in cerebellar astrocytes even though the authors did not rule out a direct action on glutamate receptors.

\section{NON GENOMIC REGULATION OF GABA AECEP- $^{-}$ TORS BY THYROID HORMONES}

\section{GABA $_{\mathrm{A}}$ Receptors: General Features}

GABA is the principal inhibitory neurotransmitter in adult mammalian brain and plays important roles also during development. Its action is mainly mediated by metabotropic $\mathrm{GABA}_{\mathrm{B}}$ and ionotropic $\mathrm{GABA}_{\mathrm{A}}$ receptors. Ionotropic $\mathrm{GABA}_{\mathrm{A}}$ receptors are heteropentameric structures derived from the assembly of different type of subunits $(\alpha, \beta, \gamma, \delta, \varepsilon)$ that confer to the receptor distinct biophysical and pharmacological features $[41,42]$. In the last years it has been recognized that $\mathrm{GABA}_{\mathrm{A}}$-mediated inhibition in the brain depends on two types of current: a phasic one mediated by synaptically released GABA and a tonic current produced by the activation of extasynaptic receptors by ambient low concentrations of GABA [43].
Synaptic and extrasynaptic $\mathrm{GABA}_{\mathrm{A}}$ receptors differ not only in their localization but also in the subunit composition, and in the biophysical and pharmacological properties [44]. Extra synaptic $\mathrm{GABA}_{\mathrm{A}}$ receptors possess higher affinity for GABA and slower rate of desensitization than synaptic ones [45]. Tonic inhibition plays a crucial role in regulating neuronal excitability because it sets the threshold for the generation of action potential and allows the integration of excitatory signals.

$\mathrm{GABA}_{\mathrm{A}}$ receptor is the target of several clinically important drugs (e.g. barbiturates, benzodiazepines, anesthetics and ethanol) and of endogenous substances (e.g. endozepines and NSs) [42, 46, 47].

NSs can act as bimodal modulators of GABAergic neurotransmission; indeed some of them potentiate $\mathrm{GABA}_{\mathrm{A}}$ receptor function (ALLO, THDOC) [47, 48, 49] while others (PS, DHEAS) decrease receptor activity [50].

\section{GABA $_{\mathrm{A}}$ Receptors and Thyroid Hormones}

The first evidence that THs could be active on $\mathrm{GABA}_{\mathrm{A}}$ receptors is from the late ' 60 s [51]. The interactions between GABAergic and thyroid system are very complex and bidirectional: THs have effects on the enzymes responsible for synthesis and degradation of GABA, levels of glutamate and GABA, release and reuptake of GABA by neurons; on the other side GABAergic system regulates the pituitary-thyroid axis at different levels [17].

The majority of these effects are mediated by transcriptional mechanisms but several reports in the last decade indicate that there is also a direct action of THs on $\mathrm{GABA}_{\mathrm{A}}$ receptors.

Martin et al. [52] showed that THs are able to modulate recombinant $\mathrm{GABA}_{\mathrm{A}}$ receptors expressed in HEK 293 cells. $\mathrm{T} 3$ and $\mathrm{T} 4$ decrease GABA-evoked current with $\mathrm{EC}_{50}$ in the low micromolar range and selectively act on certain subunit combinations. In fact, THs effect was present both on $\alpha 1 \beta 2 \gamma 2 \mathrm{~L}$ and on $\beta 2 \gamma 2$, but not on receptors assembled from 
$\alpha 6 \beta 2 \gamma 2$ subunits. THs do not bind to the benzodiazepine (BZ) site since RO15-1788, a competitive BZ antagonist, does not block their effects. In injected Xenopus oocytes THs decrease, in a non-competitive fashion, GABA-evoked current in $\alpha 1 \beta 2 \gamma 2$ but not in $\beta 2 \gamma 2$ and in $\alpha 6 \beta 2 \gamma 2$, suggesting that $\alpha 1$ subunit is important for THs modulation. In the experiments performed in oocytes $\mathrm{T} 3$ was also able to directly open the channel and this effect was present in all the $\mathrm{GABA}_{\mathrm{A}}$ subunit combination tested [53]. The fact that T3 activates the channel at the same concentrations that block the channel open by GABA is a bit surprising and raises the question of which could be the predominant effect in vivo. In other studies performed in HEK293 cells [52] and in neurons in culture [54] the direct effect of T3 was not evident. It is possible that in these systems the amount of $\mathrm{GABA}_{\mathrm{A}}$ receptor expressed is considerably lower than in injected oocytes making difficult the detection of T3-induced current that is much smaller (160 fold) than the GABA-evoked one. The agonistic effect of $\mathrm{T} 3$ was blocked by picrotoxin but not by bicuculline suggesting that it acts at a site different from the classical agonist site [53]. It is possible that $\mathrm{T} 3$, having a very low efficacy, behaves like a partial agonist, and in presence of the full agonist, i.e. GABA, antagonizes its effect. Only when the number of receptors is very high, as it happens in injected oocytes, the agonist effect is detectable.

In a very recent work, Puia et al. [54] investigated in detail THs modulation of native $\mathrm{GABA}_{\mathrm{A}}$ receptor expressed in cultured hippocampal neurons. T3 and T4 decreased GABAevoked currents with potencies in the micromolar range (Fig. $2 \mathrm{~A})$. The antagonism was non-competitive, as previously shown also by Chapel et al. [53] and Martin et al. [55].

THs modulation of $\mathrm{GABA}_{\mathrm{A}}$ receptor could depend on receptor phosphorylation [56], intracellular $\mathrm{Ca}^{2+}[37,57]$ or could be mediated by the integrin receptor $\alpha v \beta 3[19,20]$. To address these points the activity of THs was measured in presence of protein kinase blockers, of BAPTA, and of TET$\mathrm{RAC}$, a selective antagonist of the integrin receptor. None of these treatments changed the effect of the hormones [54].

Exogenous application of GABA (GABA-evoked current) recruits all $\mathrm{GABA}_{\mathrm{A}}$ receptors present on cell surface, but it is possible that THs exert a diverse modulation on synaptic vs. extra-synaptic receptors. GABA released in the synaptic cleft evokes spontaneous inhibitory postsynaptic currents (sIPSCs) that are sensitive to both hormones. The frequency and the amplitude of sIPSCs, recorded from hippocampal neurons in culture, were reduced by $\mathrm{T} 3$ or $\mathrm{T} 4$ (both at $10 \mu \mathrm{M}$ ) but the current decay was unaffected [54] (see Fig. 2B). While the decrease in current amplitude is explained by THs effect at the level of postsynaptic $\mathrm{GABA}_{\mathrm{A}}$ receptors, the reduction in frequency could depend on presynaptic mechanisms. It is possible that THs modify the release of neurotransmitter by binding to some pre-synaptic receptors regulating the GABA release or by acting at the level of cytoskeleton proteins [36, 38]. Extra-synaptic $\mathrm{GABA}_{\mathrm{A}}$ receptors are activated by low concentrations of GABA, which diffuses from the neighboring synapses, and have higher affinity for the agonist and slower rate of desensitization than synaptic $\mathrm{GABA}_{\mathrm{A}}$ receptors [45]. T3 and T4 have a diverse activity on GABA tonic current mediated by extra-synaptic receptors. $\mathrm{T} 3$, but not $\mathrm{T} 4$, reduces the current evoked by low concentration of GABA, indicating that the two hormones should have different modulatory roles on GABAergic neurotransmission.

\section{THYROID HORMONES AND NEUROSTEROIDS: SIMILARITIES AND DIFFERENCES IN THEIR AC- TIONS AT THE LEVEL OF IONOTROPIC GLUTA- MATE AND GABA RECEPTORS $^{2}$}

THs share a lot of similarity with some of the endogenous molecules called NSs [31]. In particular, the chemical structure of T3 is very close to that of the sulphate steroid pregnenolone sulfate (PS) [55], and also the modulation of THs at the level of different neurotransmitter systems is comparable to that of this NS.

PS can regulate learning and memory at low concentrations [58] and infusion of low doses (ng) of this NS into hippocampus can reverse cognitive impairment in aged rats [59]. THs deficiency impairs learning and memory in adults [9] and intra-hippocampal infusion of T3 favours LTP [60].

At the molecular level PS, similarly to T3, inhibits, in a non-competitive way, AMPA and $\mathrm{GABA}_{\mathrm{A}}$ receptors function $[50,53,54,55,61,62]$. The modulation of the $\mathrm{GABA}_{\mathrm{A}}$ receptor by both compounds does not require the presence of $\gamma$ subunit in the receptor assembly $[48,53]$, and is not mediated by the binding to the benzodiazepine site [52]. Even though the two molecules share many similarities their site of action on $\mathrm{GABA}_{\mathrm{A}}$ receptor is probably different because, when applied together at concentrations able to elicit a maximal response, they have an additive effect [54].

Hosie et al. $[63,64]$ identified three or four distinct sites for NSs in the $\mathrm{GABA}_{\mathrm{A}}$ receptors: a "potentiating" site, responsible for the positive modulatory action of ALLO and THDOC, an "acting" site, connected with the agonist activity of both compounds, and one or possibly two other sites for inhibitory sulphate steroids [65]. Further studies are needed to identify other sites in the $\mathrm{GABA}_{\mathrm{A}}$ receptor responsible for THs action.

Both THs and PS reduce GABAergic neurotransmission by decreasing sIPSCs frequency. PS effect on sIPSCS is mediated by presinaptic $\sigma 1$ receptors and is elicited by nanomolar concentrations of the NS [66], while the modulatory effect of THs is obtained at micromolar concentrations and the mechanism of action is still unknown [54].

THs, depending on the experimental system [53], could behave as agonist of the $\mathrm{GABA}_{\mathrm{A}}$ receptor and its action is blocked by picrotoxin, a non-competitive antagonist of the receptor. PS does not show agonist properties but some other NSs such as ALLO and THDOC are capable of opening $\mathrm{GABA}_{\mathrm{A}}$ channels at micromolar concentrations and their agonistic action is blocked by bicuculline [48]. Furthermore these NSs at nanomolar concentrations are positive allosteric modulators of $\mathrm{GABA}_{\mathrm{A}}$ receptor $[48,49]$.

Both THs and PS modulate NMDA receptor function, but in different way: THs inhibit NMDA receptors and this effect is independent on the subunit assemblies [34], while PS, 


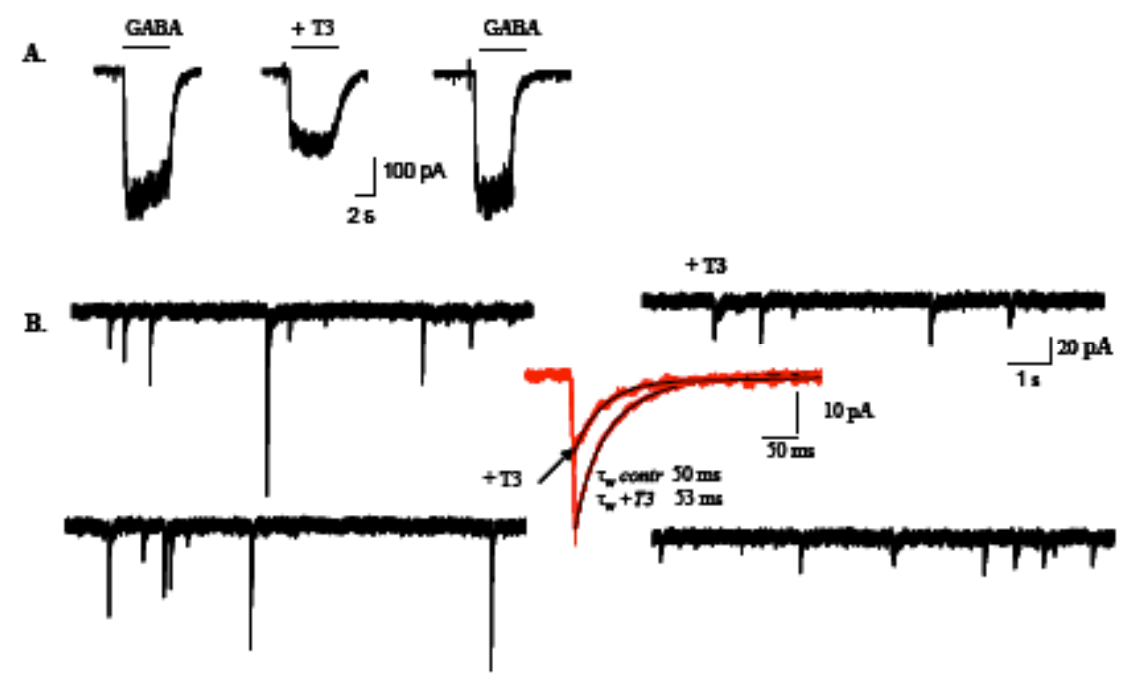

Fig. (2). Modulatory effect of THs on native $G A B A_{A}$ receptors.

A). GABA-evoked current from a cortical neuron in primary culture at $8 \mathrm{DIV}$ (days in vitro) voltage clamped at $-60 \mathrm{mV}$. Representative traces showing the response to $1 \mu \mathrm{M}$ GABA alone and in the presence of T3 $(20 \mu \mathrm{M})$ and after wash out. B). Spontaneous inhibitory postsynaptic currents (sIPSCs) recorded from a cortical neuron in culture at 12DIV. Representative traces in control conditions (CNQX $5 \mu \mathrm{M}$, MK801 $10 \mu \mathrm{M})($ left) and after bath perfusion of T3 $(10 \mu \mathrm{M})($ right). In the middle: averaged sIPSCs in control and after T3 with indication of the decay time constant $\left(\tau_{\mathrm{w}}\right)$. The current amplitude was reduced by $50 \%$ while the $\tau_{\mathrm{w}}$ was not significantly changed after T3 perfusion.

depending on the subunit combination expressed, potentiates or reduces NMDA-evoked current [61, 67, 68].

PS, like other NSs, is synthesized ex novo in the brain [31]. Previous works claimed that NSs production occurs mainly in glial cells [69], but recently evidence was provided of the expression of the neurosteroidogenic enzymes in neurons. Agis-Balboa et al. [70] reported that the synthetic en-

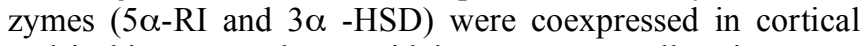
and in hippocampal pyramidal neurons as well as in output neurons of the amygdala, thalamus, cerebellum and striatum, but not in GABAergic interneurons or in glial cells [70, 71].

$\mathrm{T} 3$ and T4 are synthesized in the periphery and from the circulation enter the brain through the blood brain barrier using plasma membrane transporters. T3 present in the brain derived only partially ( $20 \%$ in fetal life) from the periphery but is produced locally from T4 by deiodinase type 2 (D2)mediated activity . D2 is present predominantly in glial cells, tanycytes and astrocytes [72] and its expression and activity is regulated by pharmacological treatments [73] and in physiological or in pathophysiological situations [74]. The expression of D2 in astrocytes suggests the existence of interplay between astrocyte and neurons in regulating THs levels. T4 and T3 are metabolized in neurons by the deiodinase type 3 (D3) in rT3 and T2 respectively. RT3 is genomically inactive but is able to modulate both GABA- and NMDA-evoked currents $[34,54]$. THs are charged aminoacid derivatives and necessitate protein carriers to cross the plasma membrane. Indeed several THs transporters have been identified [75] including monocarboxylate transporter 8 (MCT8), aminoacid transporters, and organic anion transporting polypetides (OATP14). MCT8 is a specific transporter for T4 and T3, expressed in neurons from all brain areas very sensitive to $\mathrm{THs}$ such as neocortex, hippocampus, hypothalamus and Purkinje cells [76], while OATP14, a carrier and for $\mathrm{T} 4$, is predominantly expressed in astrocytes.
The concentrations of $\mathrm{T} 3$ and $\mathrm{T} 4$ in the brain are regulated by complex mechanisms involving THs plasma membrane transport and D2 and D3 activity [77, 78]. All these findings favour the idea that THs concentrations in the brain should be not homogeneous and peaks of high concentrations could be present in selected brain areas. In Figure 3 is schematized a synapse and the putative sites of action of $\mathrm{THs}$ at this level. Different factors may concur to activate the genomic or the non genomic pathway and this issue should be further investigated.

\section{PUTATIVE ROLE OF THYROID HORMONES NON GENOMIC EFFECTS ON GLUTAMATERGIC AND GABAERGIC NEUROTRANSMISSION IN PHYSIO- LOGICAL AND PATHOLOGICAL SITUATIONS}

\section{Role of Thyroid Hormones Non Genomic Effects on} Ligand -Gated Ionotropic Receptors in Development

THs influence brain development very early in fetal life. The nuclear THs receptors are expressed in the brain as early as from the $10^{\text {th }}$ week of gestation in humans and increase during the second trimester. THs have very important actions on neuronal migration, synaptogenesis and differentiation of neurons and astrocytes. All these maturational processes are regulated in a narrow time window [2] and changes in THs level during this period may result in profound and long lasting alterations in the cytoarchitecture and functionality of the whole brain $[3,4]$.

THs differently affect GABA system in developing versus adult brain: they stimulate GABA function in development while inhibit it in adults [2]. It is known that developmental effects of THs in mammalian brain are mainly mediated by nuclear receptors regulating gene expression, even though also the non-genomic mechanisms are recognized as determinant in many developmental processes [36]. 


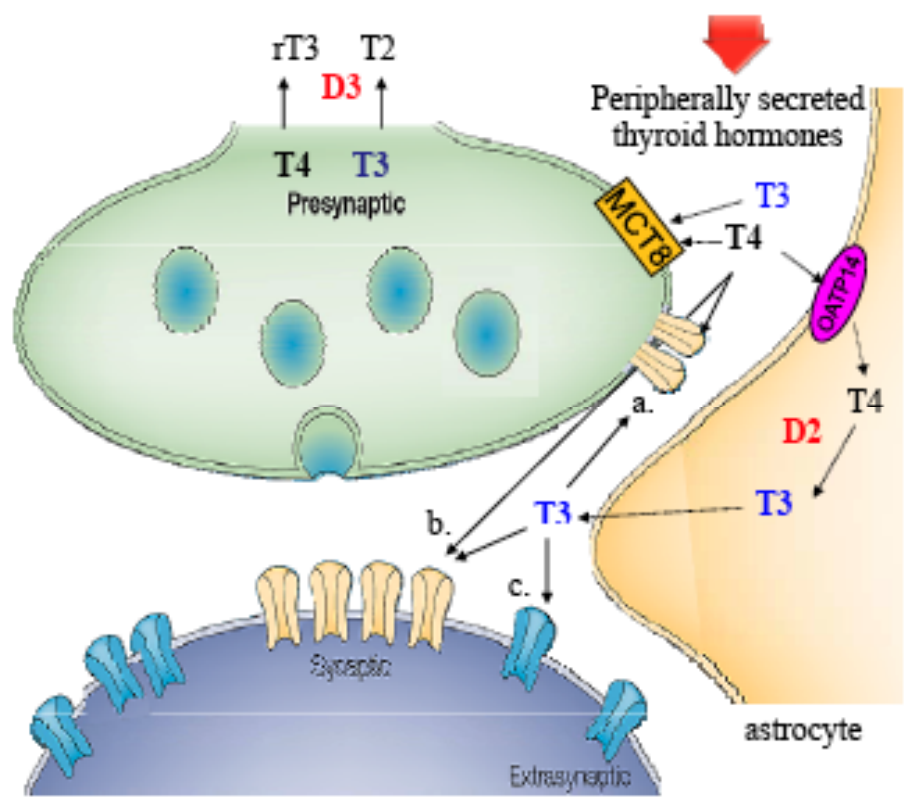

Fig. (3). Non genomic effects of THs at the level of the synapse.

Schematic view of a synapse where are evidentiated the hypothetical interaction of T3 and T4 with ligand gated ionotropic receptors. THs deriving from the periphery or T3 produced in astrocytes can modulate synaptic function in a fast way by acting at the level of presynaptic (a) postsynaptic (b) or extrasynaptic (c) receptors.

Which is the possible involvement of the nontranscriptional regulation of THs of glutamatergic and GABAergic neurotransmission in development?

Several mechanisms govern neuronal migration and among them, the activation of specific GABA and glutamate receptors is particularly important because, by acting as motility promoters, they can accelerate or stop the migration [79]. GABA and glutamate receptors are expressed in migrating neurons at early developmental stages and their activation produces changes in intracellular $\mathrm{Ca}^{2+}$ concentration. In fact, NMDA receptor is highly permeable to $\mathrm{Ca}^{2+}$ and, early in development (until P2-5 in hippocampus), GABA acts also as an excitatory neurotransmitter [79] and increases the intracellular $\mathrm{Ca}^{2+}$ concentration. Being $\mathrm{Ca}^{2+}$ very important for different cellular functions such as changes in cytoskeleton dynamics [80], the antagonism of GABA and glutamate receptors by THs could affect developmental processes. The inhibition of NMDA receptors retard cell migration because speed and direction of the process are modulated by extrinsic $\mathrm{Ca}^{2+}$ signals related to the receptor activation prior to synapses formation. Indeed, in hypo thyroidal pups the migration of glutamatergic neurons is disorganized and there is a decrease in dendritic arborization [2, $3,4,81]$.

During development, the fast modulation of synaptic transmission by THs could also operate a selection among different inputs: blockade of one synapse activity could promote the suppression of that input.

The importance of non genomic modulation of THs in adults is more acknowledged than during development. It is possible that in adult THs, as other endogenous neuromodulators, act to fine tuning inhibitory and excitatory neuro- transmission, since their effect is fast but reversible. Selective expression and activity of the synthetic and metabolic enzymes [72] and the specificity of THs action [53] prompt to think that their roles in the different brain areas may be different.

\section{Role of Thyroid Hormones Non Genomic Effects on Ligand Gated Ionotropic Receptors in Dystyroidism in Adults}

Thyroid dysfunction in adult can affect the activity of several neurotransmission [2], such as serotoninergic [82, 83, 84], adrenergic [82, 85, 86, 27] cholinergic [87, 88, 89], GABAergic and glutamatergic system, and the functional alterations consequent to this pathological situation derived by an impairment in all the systems. Pathological increase or decrease of THs modify GABAergic and glutamatergic systems; for example, hypothyroidism produces changes in the enzymes responsible for the synthesis and metabolism of GABA and glutamate, in neurotransmitter release and reuptake, in the expression and functionality of the receptors [17, 90].

All these modifications are mainly determined by the genomic effects, but it is important to know whether the non genomic actions of THs on GABAergic or glutamatergic transmission could be equally important in determining the functional changes found in dysthyroidism in adults.

Let us consider the mechanism by which hypothyroidism affects learning and memory. Many studies have shown that there is impairment in LTP in several circuits of the hippocampus in hypothyroidism. Since T3, acutely administered, can contribute to the degree of LTP [60] in euthyroidal animals, a decrease in $\mathrm{T} 3$ concentrations due to a hypo thyroidal 
state could impair LTP [11]. T3 effect could be mediated by a decrease in GABA inhibitory drive, even though other neurotransmitter systems could be involved.

Considering the different activity of $\mathrm{T} 3$ and $\mathrm{T} 4$ either on glutamatergic neurotransmission (T3 but not $\mathrm{T} 4$ reduces AMPA receptors activity) or on GABAergic neurotransmission (T3 but not T4 decrease GABA tonic current) it is very likely that, since normal activity of the brain requires certain level of $\mathrm{T} 3$ and $\mathrm{T} 4$, changes in the relative concentrations of the two hormones produce alterations in the funtionality of the brain circuitry.

Interestingly the diverse brain areas are differently affected by hypo- or hyper- thyroidism [74]. T4 and T3 concentrations and the activity of the enzymes D2 and D3 selectively change in some areas. For example in an experimental model of hyperthyroidism, the concentrations of T4 increase two to three fold in all brain regions whereas T3 levels were reduced in some areas while remaining unchanged in others such as cortex, hippocampus and amygdala that are very sensitive to THs [74]. All these data suggest that the T3 and T4 effects in the brain are very complex and that their role could be different in different brain areas.

It is also possible that the fast modulatory action of THs on neurotransmission could serve, in case of hormonal imbalance, as a compensatory mechanism to re-tune the system, but if the imbalance persists can trigger more stable changes through the activation of genomic machinery.

\section{CONCLUSIONS}

THs act as modulators of GABAergic and glutamatergic neurotransmission in vitro. Considered that their levels in the brain are finely regulated by complex mechanisms, it is plausible that they have a role as endogenous modulators of brain functions. In particular, in development through their non genomic effects, they can regulate cell migration and differentiation, while in adult life they can rapidly and finely tune the network activity of defined brain areas.

A better understanding of the non genomic mechanisms of THs at the level of diverse neurotransmitter systems are fundamental to try to correct the imbalance in brain functionality derived from pathological THs levels and eventually for the development of new therapeutic agents that could be useful in the treatments of psychiatric disorders.

\section{ACKNOWLEDGEMENTS}

The author would like to thank Dr. Giulia Curia for the editing and critical reading of the manuscript.

\section{ABBREVIATIONS}

$\begin{array}{lll}\text { 5alpha-RI }= & \text { 5alpha-reductase type I } \\ \text { 3alpha-HSD }= & \text { 3alpha-hydroxysteroid dehydrogenase } \\ \text { ALLO } & \text { Allopregnanolone }(3 \alpha \text {-hydroxy-5 } \alpha- \\ & \text { pregnan-20-one })\end{array}$

DHEAS = Dehydroepiandrosterone sulfate

GABA $=\gamma$-aminobutyric-acid

NMDA $=\mathrm{N}$-methyl-D-aspartic acid

rT3

PS

THs

T4

T3

$\mathrm{T} 2$

THDOC

$=$ Reverse-triiodothyronine

$=$ Pregnenolone sufate

$=$ Thyroid hormones

$=$ L-thyroxine

$=3,3^{\prime}, 5$-L-triiodothyronine

$=3,5$-diiodothyronine

$=$ Tetrahydrodeoxycorticosterone $(3 \alpha, 21$ dihydroxy-5 $\alpha$-pregnan-20-one)

\section{REFERENCES}

[1] Swope, S.L.; Mss, S.J.; Raymond, L.A.; Huganir, R.L. Regulation of ligand-gated ion channels by protein phosphoryation. Adv. Second Messanger Phosphoprotein Res., 1999, 33, 4-78.

[2] Ahmed, O.M.; El-Gareib, A.W.; El-Bakry, A.M.; Abd El-Tawab, S.M.; Ahmed, R.G. Thyroid hormones states and brain development interactions. Int. J. Dev. Neurosci., 2008, 26(2), 147-209.

[3] Ausò, E.; Lavado-Autric, R.; Cuevas, E.; Del Rey, F.E.; Morreale De Escobar, G.; Berbel, P. A moderate and transient deficiency of maternal thyroid function at the beginning of fetal neocorticogenesis alters neuronal migration. Endocrinology, 2004, 145(9), 40374047.

[4] Lavado-Autric, R.; Ausò, E.; Garcia-Velasco, J.V.; Arufe Mdel, C.; Escobar del Rey, F.; Berbel, P.; Morreale de Escobar, G. Early maternal hypothyroxinemia alter histogenesis and cerebral cortex cythoarchitecture of the progeny. J. Clin. Invest., 2003, 11(7), 1073-1082.

[5] Burmeister, L.A.; Ganguli, M.; Dodge, H.H.; Toczek, T.; DeKosky, S.T.; Nebes, R.D. Hypothyroidism and cognition: preliminary evidence for a specific defect in memory. Thyroid, 2001, 11, 1177-1185.

[6] Gulseren, S.; Gulseren, L.; Hekimsoy, Z.; Cetinay, P.; Ozen, C.; Tokatlioglu, B. Depression, anxiety, health-related quality of life, and disability in patients with overt and subclinical thyroid dysfunction. Arch. Med. Res., 2006, 37(1), 133-139.

[7] Akaike, M.; Kato, N.; Ohno, H.; Kobayashi, T. Hyperactivity and spatial maze learning impairment of adult rats with temporary neonatal hypothyroidism. Neurotoxicol. Teratol., 1991, 13, 317-322.

[8] Gilbert, M.E.; Sui, L. Dose-dependent reductions in spatial learning and synaptic function in the dentate gyrus of adult rats following developmental thyroid hormone insufficiency. Brain Res., 2006, 1069, 10-22.

[9] Gilbert, M.E. Alterations in synaptic transmission and plasticity in area CA1 of adult hippocampus following developmental hypothyroidism. Brain Res. Dev. Brain Res., 2004, 148(1), 11-18.

[10] Gilbert, M.E.; Paczkowski, C. Propylthiouracil (PTU)-induced hypothyroidism in the developing rat impairs synaptic transmission and plasticity in the dentate gyrus of the adult hippocampus. Dev. Brain Res., 2003, 145, 19-29.

[11] Sui, L.; Gilbert, M.E. Pre and posnatal PTU-induced hypothyroidism impairs synaptic transmission and plasticity in area CA1 of the neonatal rat hippocampus. Endocrinology, 2003, 144, 4195-4203.

[12] Sui, L.; Anderson, W.L.; Gilbert, M.E. Pre and posnatal PTUinduced hypothyroidism impairs synaptic transmission and plasticity in area CA1 following developmental thyroid hormone insufficiency. Toxicol. Sci., 2005, 85, 647-656.

[13] Gerges, N.Z.; Stringer, J.L.; Alkadhi, K.A. Combination of hypothyroidism and stress abolishes early LTP in the CA1 but not dentate gyrus of hippocampus of adult rats Brain Res., 2001, 922, 250260.

[14] Alzoubi, K.H.; Gerges, N.Z.; Alkadhi K.A. Levothyroxin restores hypothyroidism- induced impairment of LTP of hippocampal CA1: electrophysiological and molecular studies. Exp. Neurol., 2005, $195,330-341$. 
[15] Bliss, T.V.; Collingridge, G.L. A synaptic model of memory: long term potentiation in the hippocampus. Nature, 1993, 361(6407), 31-39.

[16] Gerges, N.Z.; Alkadhi, K.A. Hypothyroidism impairs late LTP in CA1 region but not in dentate gyrus of the intact hippocampus : MAPK involvement. Hippocampus, 2004, 14, 40-45.

[17] Wiens, S.C.; Trudeau, V.L. Thyroid hormone and gammaaminobutyric acid (GABA) interactions in neuroendocrine systems. Comp. Biochem. Physiol. A Mol. Integr. Physiol., 2006, 144(3), 332-344.

[18] Ahmed, O.M.; Abd El-Tawab S.M.; Ahmed, R.G. Effects of experimentally induced maternal hypothyroidism and hyperthyroidism on the development of rat offspring: I. The development of the thyroid hormones-neurotransmitters and adenosinergic system interactions. Int. J. Dev. Neurosci., 2010, 28(6), 437-454

[19] Bergh, J.J.; Lin, H.Y.; Lansing, L.; Mohamed, S.N.; Davis, F.B.; Mousa, S.; Davis, P.J. Integrin $\alpha \mathrm{V} \beta 3$ contains a cell surface receptor site for thyroid hormone that is linked to activation of mitogenactivated protein kinase and induction of angiogenesis. Endocrinology, 2005, 146(7), 2864-2871.

[20] Davis, P.J.; Davis, F.B.; Cody, V. Membrane receptors mediating thyroid hormone action. Trends Endocrinol. Metab., 2005, 16, 429435.

[21] Cheng, S-Y.; Leonard, J.L.; Davis, P.J. Molecular aspects of thyroid Hormone actions. 2010, Endocrine Rev., 31(2), 139-170.

[22] Dratman, M.B.; Crutchfield, F.L.; Axerold, J.; Colburn, R.W.; Thoa, N. Localization of triiodothyronine in nerve ending fractions of rat brain. Proc. Nat. Acad. Sci. USA, 1976, 73, 941-944.

[23] Mason, G.A.; Walker, C.H.; Prange, A.J. L-Triiodothyronine: is this peripheral hormone a central neurotransmitter? Neuropsychopharmacology, 1993, 8, 253-258.

[24] Dratman, M.B.; Futaesaku, Y.; Crutchfield, F.L.; Berman, N.; Payne, B.; Sar, M.; Stumf, W.E. Iodine-125-labeledtriiodothyronine in rat brain: evidence for localization in discrete neural systems. Science, 1982, 215, 309-312.

[25] Rozanov, C.B.; Dratman, M.B. Immunohistochemical mapping of brain triiodothyronine reveals prominent localization in central noradrenergic system. Neuroscience, 1996, 74(3), 897-915.

[26] Scanlan, T.S.; Suchland, K.L.; Hart, M.E.; Chiellini, G.; Huang, Y.; Kruzich, P.J.; Frascarelli, S.; Crossley, D.A.; Bunzow, J.R.; RoncaTestoni, S.; Lin, E.T.; Hatton, D.; Zucchi, R.; Grandy, D.K. 3Iodothyronamine is an endogenous and rapid-acting derivative of thyroid hormone. Nat. Med., 2004, 10(6), 638-642.

[27] Gompf, H.S.; Greenberg, J.H.; Aston-Jones, G.; Ianculescu, A.G.; Scanlan, T.S.; Dratman, M.B. 3-Monoiodothyronamine: the rationale for its action as an endogenous adrenergic-blocking neuromodulator. Brain Res., 2010, 1351, 130-140.

[28] Caria, M.A.; Dratman, M. B.; Kow, L.M.; Mameli, O.; Pavlides, C. Thyroid hormone action: non genomic modulation of neuronal excitabilityin the hippocampus. J. Neuroendocrinology, 2009, 21, 98107.

[29] Patel, A.J.; Smith, R.M.; Kingsbury, A.E.; Hunt A, ; Balázs, R. Effects of thyroid state on brain development: muscarinic acetylcholine and GABA receptors. Brain Res., 1980, 198(2), 389-402.

[30] Traynelis, S.F.; Wollmuth, L.P.; McBain, C.J.; Menniti F.S.; Vance, K.M.; Ogden K.K.; Hansen, K.B.; Yuan H. Myers S.J. Dingeldine, R. Glutamate receptor ion channels: structure, regulation, and function Pharmacol. Rev., 2010, 62, 405-496.

[31] Baulieu, E.E. Neurosteroids: a novel function of the brain. Psychoneuroendocrinology, 1998, 23, 963-987.

[32] Rupprecht, R.; Holsboer, F. Neuroactive steroids: mechanisms of action and neuropsychopharmacological perspectives. Trends Neurosci., 1999, 22(9), 410-416.

[33] Oguro, K.; Ito, M.;Tsuda, H.;Mutoh, K.;Shiraishi, Y.; Mikawa, H. Interactions of thyroid hormones with $\mathrm{L}-(3 \mathrm{H})$ glutamate binding ste, with special reference to N-methyl-D-aspartate receptors Res. Commun. Chem. Pathol. Pharmacol., 1989, 65(2), 181-196.

[34] Losi, G.; Garzon, G.; Puia, G. Nongenomic regulation of glutamatergic neurotransmission in hippocampus by thyroid hormones. Neuroscience, 2008, 15l(1), 155-163.

[35] Monnet, F.P.; Maurice, T. The sigma1 protein as a target for the non-genomic effects of neuro(active)steroids: molecular, physiological, and behavioral aspects J. Pharmacol. Sci., 2006, 100(2), 93-118.

[36] Farwell, A.P.; Dubord-Tomasetti , S.A.; Pietrzykowski, A.Z.; Stachelerk, S.J.; Leonard, J.L. Regulation of cerebellar neuronal migration and neurite outgrowth by Thyroxine and 3,3,5- triiodothyronine. Brain Res. Dev. Brain Res., 2005, 154, 121-135.

[37] Zamoner, A.; Frasson Corbellini P.; Funchal C.; Menegaz D.; Mena Barretto Silva F.R.; Pessoa-Pureur, R. Involvment of calcium-dependent mechanisms on the action of $\mathrm{T} 3$ in the in vitro phosphorylation of vimentin of immature rat testis. 2005, Life Sci., 77, 3321-3335.

[38] Zamoner, A.; Funchal C.; ;Heimfarth L.; Silva F.H.; Pessoa-Pureur R. Short term effects of thyroid hormones on cythoscheletal proteins are mediated by GABAergic mechanisms in slices of cerebral cortex from young rats. 2006, Cell. Mol. Neurobiol., 26, 209- 223.

[39] Choi, D.W. Calcium and excitotoxic neuronal injury. Ann. NY Acad. Sci., 1994, 747, 162-171.

[40] Mendes-de-Aguiar, C.B.; Alchini, R.; Decker H.; Alvarez-Silva, M.; Tasca, C.I.Goncalvez Trentin A.G. Thyroid hormones increases astrocytic glutamate uptake and protects astrocytes and neurons against glutamate toxicity. J. Neurosci. Res., 2008, 86, 3117-3125.

[41] Puia, G.; Vicini, S.; Seeburg, P.H.; Costa, E. Influence of recombinant GABAA receptor subunit composition on the allosteric modulators of GABA-gated Cl- currents. Mol. Pharm., 1991, 39, 691696.

[42] Möhler, H. The rise of a new GABA pharmacology. Neuropharmacolgy., 2011, 60(7-8), 1042-1049.

[43] Farrant, M.; Nusser, Z. Variations on an inhibitory theme: phasic and tonic activation of $\mathrm{GABA}_{\mathrm{A}}$ receptors. Nat. Rev. Neurosci., 2005, 6(3), 215-229.

[44] Nusser, Z.; Mody, I. Selective modulation of tonic and phasic inhibitions in dentate gyrus granule cells. J. Neurophysiol., 2002, 87(5), 2624-2628.

[45] Brickley, S.G.; Cull-Candy, S.G.; Farrant, M. Single channel properties of synaptic and extrasynaptic receptors suggest differential targeting of receptor subtypes. J. Neurosci., 1999, 19(8), 29602973.

[46] Rothstein, J.D.; Garland, W.; Puia, G.; Guidotti, A.; Weber, R.J.; Costa E. Purification and characterization of naturally occurring benzodiazepine receptor ligands in rat and human brain. J. Neurochem., 1991, 58(6), 2102-2115.

[47] Belleli, D.; Lambert, J.J. Neurosteroids: endogenous regulators of the $\mathrm{GABA}_{\mathrm{A}}$ receptor. Nature Rev., 2005, 6, 565-575.

[48] Puia, G.; Santi, M.R.; Vicini, S.; Pritchett, D.B.; Purdy, R.H.; Paul, S.M.; Seeburg P.H.; Costa, E. Neurosteroids act on recombinant human GABA ${ }_{\mathrm{A}}$ receptors. Neuron, 1990, 4, 759-765.

[49] Puia, G.; Ducic, I.; Vicini, S.; Costa, E. Does neurosteroid modulatory efficacy depend on $\mathrm{GABA}_{\mathrm{A}}$ receptor subunit composition? Receptor Channels, 1993, 1, 135-142.

[50] Majewska, M.D.; Mienville, J.M.; Vicini, S. Neurosteroid pregnenolone sulfate antagonizes electrophysiological responses to GABA in neurons. Neurosci. Lett., 1988, 90 , 279-284.

[51] Ramírez de Guglielmone, G.C.J. Influence of neonatal hypothyroidism on amino acids in developing rat brain. $J$ Neurochem., 1966, 13(10), 1025-1125.

[52] Martin, J.V.; Williams, D.B.; Fitzgerald, R.M.; Im, H.K.; Vonvoigtlander, P.F. Thyroid hormonal modulation of the binding and activity of the $\mathrm{GABA}_{\mathrm{A}}$ receptor complex of brain. Neuroscience, 1996, 73, 705-713.

[53] Chapell, R.; Martin, J.; Machu, T.K.; Leidenheimer, N.J. Direct channel-gating and modulatory effects of triiodothyronine on recombinant $\mathrm{GABA}_{\mathrm{A}}$ receptor. Eur. J. Pharmacol., 1998, 349(1), $115-121$

[54] Puia, G.; Losi, G. Thyroid hormones modulate $\mathrm{GABA}_{\mathrm{A}}$ receptormediated currents in hippocampal neurons. Neuropharmacology, 2011, 60(7-8), 1254-1261.

[55] Martin, J.V.; Padron, J.M.; Newman, M.A.; Chapell, R.; Leidenheimer, N.J.; Burke, L.A. Inhibition of the activity of the native gamma-aminobutyric acid A receptor by metabolites of thyroid hormones: correlations with molecular modeling studies. Brain Res., 2004, 1004(1-2), 98-107.

[56] Sarkar, P.K.; Durga, N.D.; Morris, J.J.; Martin, J.V. In vitro thyroid hormone rapidly modulates protein phosphorylation in cerebrocortical synaptosomes from adult rat brain. Neuroscience, 2005, 137(1), 125-132.

[57] Sarkar, P.K. L-Triodothyronine differentially and non genomically regulates synaptosomal protein phoshorylation in adult rat brain cerebral cortex: role of calcium and calmodulin. Life Sci., 2008, 82, 920-927. 
[58] Flood, J.F.; Moreley, J.E.; Roberts, E. Memory enhancing effects in male mice of pregnenolone and steroids metabolically derived from it. Proc. Natl. Acad. Sci. USA, 1992, 89,1567-1571.

[59] Vallée, M.; Mayo, W.; Darnaudéry, M.; Corpéchot, C.; Young, J.; Koehl, M.; Le Moal, M.; Baulieu, E.E.; Robel, P.; Simon, H. Neurosteroids: deficient cognitive performance in aged rats depends on low pregnenolone sulfate levels in the hippocampus. Proc. Natl. Acad. Sci. USA, 1997, 94(26), 14865-14870.

[60] Tang, Y.P.; Ma, Y.L.; Chen, S.K.; Lee, E.H. mRNA differential display identification of thyroid hormone-responsive protein (THRP) gene in association with early phase of long term potentiation. Hippocampus, 2001, 11, 637-646.

[61] Wu, F.S.; Gibbs, T.T.; Farb, D. Pregnenolone sulfate: a positive allosteric modulator at the NMDA receptor. Mol. Pharmacol., 1991, 40, 333-336.

[62] Majewska, M.D. Neurosteroids: endogenous bimodal modulators of the $\mathrm{GABA}_{\mathrm{A}}$ receptor. Mechanism of action and physiological significance Prog. Neurobiol., 1992, 38, 379-395.

[63] Hosie, A.M.; Wilkins, M.E.; da Silva, H.M.A.; Smart, T. Endogenous neurosteroids regulate $\mathrm{GABA}_{\mathrm{A}}$ receptors through two discrete transmembrane sites. Nature, 2006, 444, 486-489.

[64] Hosie, A.M.; Clarke, L.; da Silva, H.; Smart, T. Consered site for neurosteroid modulation of $\mathrm{GABA}_{\mathrm{A}}$ receptors. Neuropharmacology, 2009, 56, 149-154.

[65] Hosie, A.M.; Wilkins, M.E.; Smart, T. Neurosteroid binding stes on $\mathrm{GABA}_{\mathrm{A}}$ receptors. Pharmacol. Ther., 2007, 116, 7-19.

[66] Mtchedlishvili, Z.; Kapur, J.A. Presynaptic action of the neurosteroid pregnenolone sulfate on GABAergic synaptic transmission. Mol. Pharmacol., 2003, 64, 857-864.

[67] Malayev, A.; Gibbs, T.T.; Farb, D. Inhibition of the NMDA response by pregnenolone sulphate revels subtype selective modulation of NMDA receptors by sulphated steroids. Br. J. Pharmacol., 2002, 135, 901-909.

[68] Zaman, S.H.; Shingai, R. ; Harvey, R.J.; Darlison,M.G.; Barnard, E.A. Effect of subunit types of recombinant $\mathrm{GABA}_{\mathrm{A}}$ receptor on the response to a neurosteroid. Eur. J. Parmacol., 1999, 225, 321330.

[69] Mellon,S:H.; Deschepper, C.G. Neurosteroid biosynthesis:genes for adrenal sterodogenic enzymes are expressed in the brain. Brain Res., 1993, 629, 283-292.

[70] Agis-Balboa, R.C.; Pinna, G.; Zhubi, A.; Maloku, E.; Veldic, M.; Costa, E.; Guidotti, A. Characterization of brain neurons that express enzymes mediating neurosteroid biosynthesis. Proc. Natl. Acad. Sci. USA, 2006, 103, 14602-14607.

[71] Pinna, G.; Agis-Balboa, R.C.; Pibiri, F.; Nelson, M.; Guidotti, A.; Costa, E. Neurosteroid biosynthesis regulates sexually dimorphic fear and aggressive behavior in mice. Neurochem. Res., 2008, 33, 1990-2007.

[72] Guadaño -Ferraz, A.; Obregón, M.J.; St Germain, D.L.; Bernal, J. The type 2 iodothyronine deiodinase is expressed primarily in glial cells in the neonatal rat brain. Proc. Natl. Acad. Sci. USA, 1997, 94, 10391-10396.

[73] Eravci, M.; Pinna, G.; Meinhold, H.; Baumgartner, A. Effect of Pharmacological and nonpharmacological treatments on thyroid hormone metabolism and concentrations in rat brain. Endocrinology, 2000, 141, 1027-1040.
[74] Broedel, O.; Eravci, M.; Fuxius, S.; Smolarz, T.; Jeitner, A.; Grau, H.; Stoltenburg-Didinger, G.; Plueckhan, H.; Meinhold, H.; Baumgartner, A. Effect of Hyper and hypothyroidism on thyroid hormone concentrations in regions of the rat brain. Am. J. Physiol. Endocrinol. Metab., 2003, 285, E470-E480.

[75] Heuer, H.; Maier M.K.; Iden, S.; Mittag, J.; Friesema, E.C.H.; Visser, T.J.; Bauer, K. The monocarboxylate transporter 8 linked to human pschomotor retardation is highly expressed in thyroid hormone-sensitive neuron population. Endocrinology, 2005, 146, 1701-1706

[76] Bernal, J. Action of thyroid hormone in brain. J. Endocrinol. Invest., 2002, 25(3), 268-288.

[77] Leonard, J.L.; Kohrle, J. Intracellular pathway of iodothyronine metabolism. In: The Thyroid; Braverman L.E.; Utinger R.D, $8^{\text {th }}$. Philadelphia, 2000, 136-171.

[78] St Germain, D.L.; Galton, V.A.; Hernandez, A. Defining the roles of the iodothyronine deiodinase: current concepts and challenges. Endocrinology, 2009, 150, 1097-1107.

[79] Ben Ari, Y.; Gaiarsa, J.L.; Tyzio, R.; Khazipov, R. GABA: a pioneer transmitter that excites immature neurons and generates primitive oscillations. Physiol. Rev., 2007, 87, 1215-1284.

[80] Manent, J.B.; Represa, A. Neurotransmitters and brain maturation:early paracrine actions of GABA and glutamate modulate neuronal migration. Neuroscientist, 2007, 13(3), 268-269.

[81] Legrand, J. Thyroid hormones and maturation of the nervous system. J.Physiol., 1982, 78, 603-652.

[82] Lifschytz, T.; Segman, R.; Shalom, G.; Lerer, B.; Gur, E.; Golzer, T.; Newman, M.E. Basic mechanism of augmentation of antidepressant effects with thyroid hormone. Curr. Drug Targets, 2006 , 7(2), 203-210.

[83] Mason, G.A.; Bondy, S.C.; Nemeroff, C.B.; Walker, C.H.; Prange, A.J., Jr. The effects of thyroid state on beta-adrenergic and serotonergic receptors in rat brain. Psychoneuroendocrinology, 1987, 12(4), 261-270.

[84] Bauer, M.; Heinz, A., Whybrow, P.C. Thyroid hormones, serotonin and mood: of synergy and significance in the adult brain. Mol. Psychiatry, 2002, 7, 140-156.

[85] Silva, J.E.; Bianco, S.D. Thyroid-adrenergic interactions: physiological and clinical implications. Thyroid, 2008, 18(2), 157-165.

[86] Kundu, S.; Biswas, A.; Roy, S.; De, J.; Pramanik, M.; Ray, A.K. Thyroid hormone homeostasis in brain: possible involvement of adrenergic phenomenon in adult rat. Neuroendocrinology, 2009, 89(2), 140-151.

[87] Hayashi, M.; Patel, A.J. An interaction between thyroid hormone and nerve growth factor in the regulation of choline acetyltransferase activity in neuronal cultures, derived from the septaldiagonal band region of the embryonic rat brain. Brain Res., 1987, 433(1), 109-120.

[88] Sarkar, P.K.; Ray, A.K. Involvement of L-tiiodothyronine in acetiylcohline metabolism in adult rat cerebrocortical synaptosomes. Horm. Metab. Res., 2001, 33, 270-275.

[89] Smith, J.W.; Evans, A.T.; Costall, B.; Smythe, J.W. Thyroid hormones, brain function and cognition: a brief review. Neurosci. Biobehav. Rev., 2002, 26(1), 45-60.

[90] Lee, P.R.; Brady, D.; Koenig, J.I. Thyroid hormone regulation of $\mathrm{N}$-methyl-D-aspartic acid receptor subunit mRNA expression in adult brain. $J$. Neuroendocrinol., 2003, 15(1), 87-92. 